
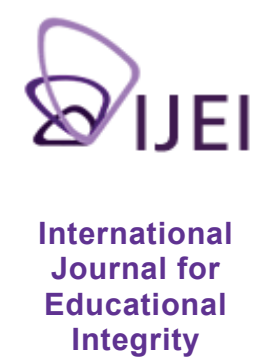

\title{
Can we reliably determine intent in cases of plagiarism?
}

\author{
Jon Yorke (corresponding author) \\ Curtin University of Technology, Perth, Australia \\ j.yorke@curtin.edu.au \\ (+618) 92661735 \\ Kathryn Lawson \\ Curtin University of Technology, Perth, Australia \\ Kathryn.Lawson@curtin.edu.au \\ (+618) 92667188 \\ Graham McMahon \\ Curtin University of Technology, Perth, Australia \\ g.mcmahon@curtin.edu.au \\ (+618) 92667013
}

Keywords: plagiarism, determining intent, probability factors

\begin{abstract}
A review of the literature relating to plagiarism suggests that there is substantial variability in approach between institutions. Some institutions tend to view all occurrences of plagiarism as academic misconduct, whilst others take a more graded view - articulated through policy and procedures that aim to quantify 'levels' of severity. Measured approaches such as these tend to rely on guides to help assess the level of severity, typically encompassing the experience of the student, the amount of material plagiarised, and the likelihood of an intention to deceive. Such judgements lead to a graded response to the student which can result in a wide range of outcomes, from educational guidance and support to expulsion from the institution.

However, the intent to deceive can be extremely difficult to establish. This paper will draw on a desktop study of institutional policies and procedures in Australia and other countries to sample and summarise the myriad approaches to the definition and determination of (specifically) intent in plagiarism. Based on the findings of this review, we suggest that the treatment of intent is, at best, rather inconsistent. A series of 'probability factors' are proposed to guide further research in this area.
\end{abstract}

\section{Introduction}

There are many reasons why students submit work that is subsequently considered to be plagiarised. A spread of factors including those relating to student familiarity with academic practice, time management, financial pressures, cultural norms, motivation, opportunity and risk of detection are identified in the literature (see, for example, Park, 2003; Bennett, 2005). Some of these factors are associated with what might be termed 'inadvertent' plagiarism; others relate to intentional and deceptive practice.

The International Journal for Educational Integrity is available online at:

http://www.ojs.unisa.edu.au/journals/index.php//JEl/

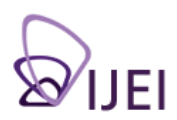


Many universities include reference to 'intent' in some way when describing their responses to plagiarism. However, few have attempted to amplify a definition of intent to include guidance on how it can be established or assessed. This paper investigates and reports on the differences between institutions in terms of the role played by the concept of 'intent', and establishes a draft set of 'probability factors' that may be useful in the determination of intent. Whilst it is acknowledged that there are many underpinning variables that influence an individual's intention to plagiarise (some of which may be highly mitigating in terms of deciding the appropriate response), a discussion of these lie outside the scope of this paper.

Legally, intent is viewed as being a dichotomous variable, although others have argued that intent is better described in terms of a continuum taking into account social contextual factors (Rosedale, 1989). In universities, plagiarism occupies a somewhat ambiguous position given that it is an institutional definition rather than a legal one (such as that described by copyright law, for example). As a result, variations in local practices abound, however the establishment of a 'balance of probability' rather than definitive 'proof' is the norm (Carroll, 2007).

A number of factors are identified in the literature relating to the establishment of that balance of probability. Carroll (2007) identifies a number of factors including the presence of deliberate attempts to conceal, the experience of the student and the extent of the copied material. Yeo and Chien (2005) discuss a staff decision-making tool based on four continua (one of which is intent) with hallmark descriptors associated with three broad levels of 'seriousness'.

Notably, these are all factors that stand separately from any admission of intent on the part of the student. In contrast, other approaches (such as that described by AUTC, 2002) propose asking the student whether they understood that it was inappropriate to use the work without attribution.

There are problems associated with placing an emphasis on a student admission of intent. It is very likely that the institutional context will determine how this may play out in practice, especially in situations where an admission of guilt will lessen the maximum penalty. Observations relating to an individual's desire to minimise a maximum loss, somewhat akin to the oft cited 'Prisoner's Dilemma' (described by Axelrod, 2006 amongst others) are pertinent here. As Carroll (2007) points out, student confessions are problematic in cases where an admission of intent is not supported by a close inspection of the evidence. The role that intent plays in terms of an institutional response is neatly summarised by Devlin (2002) in Figure 1. Note that where the extent of plagiarism is high, the presence or absence of intent has a profound consequence on the actions taken, although as Devlin (2002) asserts: "punitive and educative responses should not be seen as mutually exclusive".

\begin{tabular}{|c|c|c|}
\hline $\begin{array}{l}\text { Entirely } \\
\text { Deliberate }\end{array}$ & $\begin{array}{l}\text { Unacceptable, even if } \\
\text { minor. However, focus on } \\
\text { education rather than } \\
\text { punishment. }\end{array}$ & $\begin{array}{l}\text { This is a serious and } \\
\text { inexcusable bre ach: } \\
\text { Penalise quickly and } \\
\text { appropriately }\end{array}$ \\
\hline $\begin{array}{l}\text { Student intent } \\
\text { to plagiarise }\end{array}$ & \multicolumn{2}{|c|}{$\begin{array}{l}\text { Suggested primary } \\
\text { focus of response }\end{array}$} \\
\hline \multirow[t]{2}{*}{$\begin{array}{l}\text { Entirely } \\
\text { Accidental }\end{array}$} & $\begin{array}{l}\text { Don't ignore: Focus on } \\
\text { re-educating and on } \\
\text { explaining expectations }\end{array}$ & $\begin{array}{l}\text { Likely a significant } \\
\text { misunderstanding: } \\
\text { Renew educ ation on } \\
\text { expectations }\end{array}$ \\
\hline & $\begin{array}{l}\text { Extent of } \\
\text { Plagiarism }\end{array}$ & Extreme \\
\hline
\end{tabular}

Figure 1: Plagiarism intent/extent and suggested response (from Devlin, 2002) 
Research reported by Bermingham, Watson and Jones (2009) in their study of law schools in 48 United Kingdom (UK) higher education institutions suggests that the pattern of response described in Figure 1 is not atypical. Bermingham et al. describe nine key factors that are used to distinguish a major incident of plagiarism from one that is minor: of these factors, four could be categorised as belonging within the broader construct of intent.

Macdonald and Carroll (2006) describe processes at a post-1992 UK university and cite four factors (one of which relates to intent) used to decide the level of seriousness of plagiarism. Five prescribed possible outcomes ranging from educative advice to zero marks for that unit/module are available for selection by specialist officers. Yeo and Chien (2005) describe processes in an Australian university that also use intent as one of four factors used to determine the penalty. Significantly, Yeo and Chien also report analyses of staff confidence in the decision-making process including inter-rater consistency, suggesting that staff were least confident (and least consistent) in their judgments relating to intent.

As institutional responses seemingly do follow the pattern described in Figure 1, there is, we argue, a strong case for establishing a set of characteristics (or 'probability factors') that can be used to establish a 'balance of probability' with respect to intent a necessary precursor for reliable decision-making.

This research sets out to evaluate whether institutional policies do in fact follow the pattern described in Figure 1, seeking to establish the role played by intent in the determination of plagiarism and the associated response. Furthermore, if intent is a primary determining factor, what guidance is offered by institutions to help staff make judgements?

\section{Method}

In the spirit of gathering data with the purpose of making recommendations for intended users (Patton, 2008) the broad approach taken by this study is to examine the relationship between policy and practice, focusing in particular on the provision of institutional guidance relating to intent.

Twenty universities were selected from various countries including Australia (9), United States (US) (6), Asia (3) and the UK (2). Australian institutions comprised all five universities from the Australian Technology Network (ATN), and four further universities from the Group of 8 (Go8). The remaining universities from the US, Asia and the UK were selected on the basis of their web prominence in terms of making plagiarism resources available online. This convenience sample (de-identified for the purpose of this paper) should therefore be treated with some caution.

In each institution the university website was searched for policies, procedures and guidance relating to plagiarism and academic misconduct. (Schools or departments within the university were considered to be beyond the scope of this initial investigation: it is recognised that this approach may exclude data present in those institutions with highly devolved structures.)

Approaches to the definition and management of plagiarism were scrutinised, with particular attention paid to material relating to intent and associated descriptions of how this might be ascertained. Key terms used in searches included plagiarism, academic integrity, academic misconduct, academic dishonesty, policy, policy and procedures, teaching and learning. In cases where nothing was readily apparent, the search was broadened to other university-wide sites, such as those associated with student learning support. 


\section{Results}

Table 1 summarises the results of this analysis of institutional policy and procedures. We found no cases where intent was used as the primary determinant as to whether plagiarism had occurred or not.

It is readily apparent that there was very little consistency of approach in the twenty institutions surveyed. Over half (12 of 20) of the sample used the presence of intent to determine the penalty that was subsequently applied. Others ( 8 of 20) seemingly did not. However despite the fact that many institutions incorporated intent into the determination of an appropriate response, only a fifth (4 of 20) of the institutions sampled attempted to define intent. Perhaps more significantly, even where intent was defined there was very little in the way of detailed guidance as to how it could be determined.

Table 2 summarises the measures used to establish intent in the four institutions (identified in Table 1) that attempted to define 'intent'. These measures broadly encompassed a group of behaviours that could be classified as deceptive, in combination with other parallel measures relating to the knowledge and awareness on the part of the student.

Table 1:

Role of 'intent' in cases of plagiarism: Institutional approaches

\begin{tabular}{|c|c|c|c|}
\hline University & $\begin{array}{l}\text { Intent determines } \\
\text { whether plagiarism } \\
\text { has occurred or not }\end{array}$ & $\begin{array}{l}\text { Intent determines sever- } \\
\text { ity of incident and na- } \\
\text { ture of response }\end{array}$ & Intent is defined \\
\hline 1. Australia & No & Yes & No \\
\hline 2. Australia & No & No & No \\
\hline 3. Australia & No & Yes & Yes \\
\hline 4. Australia & No & Yes & Yes \\
\hline 5. Australia & No & No & No \\
\hline 6. Australia & No & Yes & No \\
\hline 7. Australia & No & Yes & Yes \\
\hline 8. Australia & No & No & No \\
\hline 9. Australia & No & Yes & No \\
\hline 10. USA & No & No & No \\
\hline 11. USA & No & Yes & No \\
\hline 12. USA & No & Yes & No \\
\hline 13. USA & No & Yes & No \\
\hline 14. USA & No & No & No \\
\hline 15. USA & No & No & No \\
\hline 16. Singapore & No & No & No \\
\hline 17. Hong Kong & No & Yes & No \\
\hline 18. India & No & No & No \\
\hline 19. UK & No & Yes & No \\
\hline 20. UK & No & Yes & Yes \\
\hline Total & 0 & 12 & 4 \\
\hline
\end{tabular}


Table 2:

Measures used to establish 'intent' in selected institutional policies

\begin{tabular}{|c|c|}
\hline $\begin{array}{l}\text { University } \\
\text { (from Table 1) }\end{array}$ & Measures used to establish intent \\
\hline 3. Australia & $\begin{array}{l}\text { - } \text { student experience with university study } \\
\text { - } \text { number of previous offences } \\
\text { - } \quad \text { student learning background }\end{array}$ \\
\hline 4. Australia & $\begin{array}{l}\text { - the extent of the plagiarism } \\
\text { - amount of exposure to rules of plagiarism } \\
\text { - the experience of the student (in tertiary study) }\end{array}$ \\
\hline 7. Australia & $\begin{array}{l}\text { - } \text { previous 'convictions' } \\
\text { - experience of student } \\
\text { - } \text { assignment cover sheet signature } \\
\text { - where the plagiarism occurred } \\
\text { - evidence of another person involved } \\
\text { - extent of the copying of the material }\end{array}$ \\
\hline 20. UK & $\begin{array}{l}\text { - attempt to change words } \\
\text { - referencing skill level }\end{array}$ \\
\hline
\end{tabular}

\section{Discussion}

Bermingham et al. (2009) point to the "striking lack of parity that students experience at different institutions" and the findings of this study bear out that assertion. Differing approaches were rife: some of the universities that used intent to decide on sanctions for academic misconduct left the decision up to the relevant Head of the School and the staff member involved, whilst others had specific officers who dealt with matters of academic integrity. Often, the information provided in the policy and procedure appeared to be the only material available with which to make a decision and for eight of the twelve institutional cases where 'intent' was deemed to be of significance, guidance was neither included nor referenced in the documentation.

In the four cases where intent was included, it was separated from plagiarism due to poor understanding of academic conventions to intentional or deliberate plagiarism. Pushing the point that Bermingham et al. made earlier regarding consistency, it was interesting to note that in the study of the criteria used to measure the probability of intent there was not one item that appeared in all four universities investigated. In three of the four universities that attempted to measure intent the criteria used included the student's experience at university. Two other criteria (each appearing twice in Table 2) related to previous plagiarism and the extent of the plagiarism in question. In contrast to the range of advice reported by Bermingham et al. (2009) there was no further elaboration on the amount of material that could be used to indicate intent.

Consistent with observations made by Tennant, Rowell and Duggan (2007), we found a wide variation in terms of institutional response ranging from educative support to expulsion, depending on the severity of the plagiarism and the decision rubric in use. The existence of what Carroll (2007) has termed an institutional 'coercion' to confess was highlighted in one (Australian) policy statement that suggested that 'contrition' on the part of the student would relate to the determination of intent and the application of a reduced penalty. 
In contrast to institutional policy and guidance, the treatment of the concept of intent features rather more readily in the literature (see for example Ebert, 2008; Carroll, 2007; Nelmes, 2007). From the review of related literature and the analysis of institutional policy it is possible to identify a number of characteristics. These have been drawn together in the form of a series of 'probability factors' outlined in Table 3. An approximate potential value as a predictor is offered for discussion and further work: it is acknowledged that these weightings are imprecise in terms of their relative valency at this stage. Further research is under way to refine these initial proposals.

Table 3:

Probability factors used to determine 'intent'

\begin{tabular}{|l|l|l|}
\hline Factor & Description & $\begin{array}{l}\text { Potential } \\
\text { value as } \\
\text { predictor }\end{array}$ \\
\hline Source & $\begin{array}{l}\text { The source of the plagiarised work may relate to intent. } \\
\text { Sourcing material from an essay bank would score highly. } \\
\text { for example. }\end{array}$ & strong \\
\hline Consistency & $\begin{array}{l}\text { Inconsistency: i.e. other areas of the submitted work are } \\
\text { correctly referenced, but the plagiarised part is not. }\end{array}$ & Strong \\
\hline Collusion & $\begin{array}{l}\text { The extent to which there is evidence to suggest that } \\
\text { others were involved to a greater extent than that } \\
\text { permitted by the assessment briefing. }\end{array}$ & weak \\
\hline Extent & $\begin{array}{l}\text { The extent to which the original work was copied verbatim } \\
\text { (was the material 'adapted' or 'adopted'?). }\end{array}$ & weak \\
\hline Amount & $\begin{array}{l}\text { The amount or percentage of materially important original } \\
\text { work used without attribution. }\end{array}$ & weak \\
\hline Deception & $\begin{array}{l}\text { Dishonest paraphrasing: i.e. in written work, the student } \\
\text { seems to have attempted to hide the source. }\end{array}$ & strong \\
\hline Context & $\begin{array}{l}\text { The experience of the student in the disciplinary and cul- } \\
\text { tural requirements. }\end{array}$ & weak \\
\hline Experience & $\begin{array}{l}\text { The experience of the student in terms of being aware of } \\
\text { plagiarism requirements (prior exposure to those } \\
\text { requirements) }\end{array}$ & $\begin{array}{l}\text { weak } \\
\text { similar fabrications. }\end{array}$ \\
\hline
\end{tabular}

\section{Interim conclusions and future directions}

The determination of intent is extremely difficult, and, as this paper has argued, there is no common standard for how intent and plagiarism interrelate. In some cases institutions are poles apart in terms of the effect of intent. For some, intent defines plagiarism (Ebert, 2008; Supreme Court of Queensland, 2007) but for the institutional policies surveyed here it does not. Notwithstanding comments about sample size, Sutherland-Smith (2005) shows that differing views also prevail at an individual level. Given the implications of differential approaches and ethical considerations in terms of human rights (Macdonald \& Carroll, 2006) there is a persuasive argument here for consistency in this respect.

Consistency will, we argue, be difficult to achieve even in the presence of clearly articulated policy. Sutherland-Smith (2008) suggests that the teachers' approach to teaching will influence the students' approach to learning, and therefore their propensity to plagiarise. Song-Turner (2009) makes similar points relating to different expectations held by students and teachers. A teacher who 'delivers' and assesses 
lower level material is perhaps more likely to encounter plagiarism from students when compared to that found within a more authentic and constructivist environment. This relates to the probability factors labelled 'context' and 'experience' outlined in Table 3.

A further caveat is to be found in the concept of 'cryptomnesia' (Carpenter, 2002). This describes the phenomenon where an idea is recalled from an earlier time and mistakenly perceived as being original and new. In a similar vein, existing material may become interspersed with original material during collation if the research and organisational skills of the student are poor. In both of these cases a false determination of 'intent' may well result.

Our final remarks relate to the broader ethical context. Given the significance of intent to the decision-making process, it is surprising that a stronger focus on this aspect is not made in policy and associated guidance. Further work is also needed to establish the extent to which academic colleagues use tacit or explicit definitions of intent. To this end the researchers plan to conduct a series of interviews with a sample of staff to further illuminate this complex area. A false positive with respect to the determination of intent can lead to accusations of misconduct and subsequent draconian penalties that have long lasting effects. In the context of academic integrity, this seems to be patently unfair.

\section{Author biography}

Jon Yorke is the Assessment Manager in the Office of Teaching and Learning at Curtin University of Technology, where he takes a lead role in the development of assessment policy and effective practices. His responsibilities include chairing two university-wide committees focusing on moderation and plagiarism. Prior to joining Curtin in 2008, he was the Program Director for academic development courses at the University of Plymouth (UK). His research interests include assessment, feedback and plagiarism.

Kathryn Lawson currently works at Curtin University as a Curriculum Developer and works across the various disciplines in course review. Kathy has had extensive overseas teaching experience and has been involved with teaching English as a second language as well as teaching communication skills and information literacy, including referencing skills and avoiding plagiarism.

Dr Graham McMahon has been involved with secondary and tertiary education for 22 years, in the fields of science and computer education. Currently he is a Curriculum Developer at Curtin University of Technology, which entails working with academic staff reviewing and developing teaching/learning programs. This role includes helping staff with issues related to plagiarism, be they technical problems, providing advice when interpreting data, or serving on plagiarism case review panels.

\section{References}

Australian Universities Teaching Committee, AUTC (2002). Minimising plagiarism. Retrieved July 29, 2009, from: http://www.cshe.unimelb.edu.aul assessinglearning/03/plagMain.html

Axelrod, R. (2006). The evolution of cooperation. U.S.A, Perseus Books.

Bennett, R. (2005). Factors associated with student plagiarism in a post-1992 university. Assessment and Evaluation in Higher Education, 30(2), 137-162. Retrieved July 3, 2009, from Informa database. 
Bermingham, V., Watson, S., \& Jones, M. (2009). Plagiarism in UK law schools: Is there a postcode lottery? Assessment and Evaluation in Higher Education, iFirst 1-14. Retrieved July 3, 2009, from Informa database.

Carpenter, S. (2002). Plagiarism or memory glitch? Monitor On Psychology, 38(2). Retrieved July 3, 2009, from http://www.apa.org/monitor/feb02/glitch.html

Carroll, J. (2007). A Handbook for deterring plagiarism in higher education (2nd ed.). Oxford: Oxford Centre for Staff and Learning development.

Devlin, M. (2002). Strategies to minimise plagiarism in higher education. University of Melbourne: Centre for the Study of Higher Education.

Ebert, L. B. (2008). Does plagiarism require intent? Retrieved July 3, 2009, from http://ipbiz.blogspot.com/2008/01/does-plagiarism-requie-intent.html

Macdonald, R., \& Carroll, J. (2006). Plagiarism - a complex issue requiring a holistic institutional approach. Assessment \& Evaluation in Higher Education, 31(2), 233-245. Retrieved July 3, 2009, from Informa database.

Nelms, R. G. (2007). Review of Poshard dissertation plagiarism allegations. Retrieved July 3, 2009 from http://news. siu.edu/PoshardDissertationReviewfinal.pdf

Park, C. (2003). In other (people's) words: Plagiarism by university students literature and lessons. Assessment and Evaluation in Higher Education, 28(5), 471-488. Retrieved July 3, 2009, from Informa database.

Patton, M. Q. (2008). Utilization-focused evaluation (4th ed.). Thousand Oaks, California: Sage Publications, Inc.

Rosedale, H. L. (1989). Legal analysis of intent as a continuum emphasizing social context of volition. Cultic Studies Journal, 6(1), 25-31.

Song-Turner, H. (2009). Cheaters' superhighway. Australian Universities' Review, 51 (2), 95-96. Retrieved November 15,, 2009, from http://www.aur.org.au/ index.html

Supreme Court of Queensland (2007). Supreme Court of Queensland Decisions: Humzy-Hancock, Re [2007] QSC 34 (26 February 2007). Retrieved July 3, 2009, from http://www.austlii.edu.au/au/cases/qld/QSC/2007/34.html

Sutherland-Smith, W. (2005). Pandora's box: Academic perceptions of student plagiarism in writing. Journal of English for Academic Purposes, 4, 83-95. Retrieved July 3, 2009, from ScienceDirect database.

Sutherland-Smith, W. (2008). Plagiarism, the Internet and student learning. New York: Routledge.

Tennant, P., Rowell, G., \& Duggan, F. (2007). Academic misconduct benchmarking research project: Part I - The range and spread of penalties available for student plagiarism among UK higher education institutions. Retrieved August 10, 2009, from http://www.jiscpas.ac.uk/AMBeR/index.php

Yeo, S., \& Chien, R. (2005). The seriousness of plagiarism incidents: making consistent decisions across a university. Proceedings of the 2 nd Asia-Pacific Educational Integrity Conference, University of Newcastle, Australia, 2-3 December 2005. Retrieved July 3, 2009 from http://www.newcastle.edu.au/ conference/apeic/papers_pdf/yeo\%20and\%20chien.pdf 